\title{
20 Radical Interpretation, Feminism, and Science
}

\author{
Sharyn Clough
}

\section{Introduction}

Donald Davidson's philosophy of language provides a rich array of conceptual tools for feminist science studies. In this essay, I focus on Davidson's account of radical interpretation and the concept of triangulation as a necessary feature of communication and the formation of beliefs.

The basic features of triangulation relevant to this discussion arise out of Davidson's thought experiment, building from W. V. O. Quine, concerning the interpretational strategies of the radical interpreter-an adult who finds herself in the midst of speakers of a language completely foreign to her. ${ }^{1}$ In the absence of a translation manual or any collateral information about the new language, how, Davidson asks, must this idealized interpreter proceed to cope with her unfamiliar world? Initially, all she has to go on, and, indeed, all she needs, says Davidson, is the development of a triangular relationship between (i) the beliefs of native speakers expressed as sentences, (ii) the features of the world to which the sentences refer, and (iii) her attention to (i) and (ii).

There are two important implications of this model of belief formation for feminists studying the effects of social location on knowledge production generally, and the production of scientific knowledge in particular.

The first is Davidson's argument that whatever there is to the meaning of any of our beliefs must in principle be available from the radical interpreter's external, third-person perspective. We can all imagine and/or have experienced successful immersion experiences in completely unfamiliar language communities. On what can this success depend? Surely not on some internal private stock of beliefs about, or expressed in, the new language that are then tested; initially in these situations, we, as radical interpreters, have no such semantic content available to us in the new language. Yet eventually we can, or at least we know people who have, learned the 
new language. The reason is that, in the simplest cases, at least, the content of the beliefs of the native speakers can be publicly accessed through radical interpretation. There is some debate about the role of radical interpretation in the language acquisition of children, but, in principle if not always in practice, the lesson remains. ${ }^{2}$ Although beliefs are held by individuals and are, in some sense, idiosyncratic and/or a product of particular social forces and locations that may not be shared by everyone, still, the content of any belief must in principle be publicly accessible and communicable, for it is the public process of communication that gives rise to those beliefs in the first place. And if the content of a belief can be publicly accessed, then the relationship between the content of the belief and the features of the world to which it refers, more or less directly, can be adjudicated by anyone who cares enough to take the time to do so.

This lesson responds to those critics of feminist science studies who argue that by identifying gender, for example, as playing an important role in scientific theory formation and testing, feminists are committing themselves to an incoherent conceptual relativism. Of course, some feminist articulations of the role of gender in science might commit themselves in this way (see, e.g., my discussion of Sandra Harding's work, below), but there is nothing about the acknowledgment of the role of social location in knowledge that forces such a commitment, and no one involved in feminist science studies (certainly not Harding) would endorse the commitment. If Davidson is right, the radical conceptual relativism that results from the view that believers from different social locations, such as different genders, somehow live in different and incommensurable conceptual worlds simply cannot arise, at least not in any philosophically interesting way, and certainly not in a way that would damage the epistemic authority of feminist claims. ${ }^{3}$

The second important implication of triangulation for feminist science studies is that Davidson's is a holistic model that shows there is no principled, substantive difference in the triangulation process by which we form beliefs concerning basic descriptive features of the world and beliefs concerning evaluative features of the world. ${ }^{4}$ That is, just as with descriptive judgments, feminist and other value judgments generally get their semantic content from their relationship to the world-a relationship that can in principle be objectively adjudicated. In this way, we can show that what makes feminist interpretations of particular scientific studies better than sexist interpretations is that the feminist interpretations are more empirically adequate; and the notion of empirical adequacy at work can be objectively adjudicated even by those who do not share feminist value 
frameworks. The key to such objective adjudication is not that the knower be neutral or value-free-that is impossible-but instead that the knower be impartial in her assessment of the evidence for or against a particular value judgment. The important distinctions between the impossible task of being neutral and the crucial task of being impartial, tentative, or nondogmatic are discussed by a number of philosophers who write about feminism, values, and science. ${ }^{5}$

\section{Feminism and Relativism}

I begin with the first implication of triangulation: the antirelativist point that the content of any one of our beliefs must in principle be publicly accessible and communicable; and that the truth of that belief must be available for adjudication by anyone, irrespective of his or her social location. Of course, those interpreting and adjudicating need to care enough to take the time to trace the often complex links between the content of the belief and the features of the world to which it refers, more or less directly. This is a nontrivial, practical problem to which I return below in the section entitled "Feminist Strategy."

As expressed by Helen Longino in her essay "Essential Tensions," feminists engaged in science studies have to reconcile what seem to be two conflicting claims: "that scientific inquiry is value- or ideology-laden and that it is productive of knowledge." ${ }^{\prime \prime}$ The values with which science is "laden" arise partly as a result of the social location of scientists. One of the stumbling blocks to reconciling the role of values in producing legitimate knowledge claims, then, is the problem of articulating a model of knowledge that shows how people from different social locations can share objective epistemic standards-that conceptual-scheme relativism is a nonstarter. Many feminists involved in science studies have shown a commitment to the claim that although the social location of knowers is relevant to the knowledge produced, this relevance does not radically foreclose the possibility of sharing objective epistemological standards between those who are working from different social locations. Feminist interpretations of particular studies are empirically better than sexist interpretations-and not better according to feminist epistemological standards, understood as subjective and relativistic, but better according to objective standards held by feminists and in principle available to any knower.

In her landmark essay "Situated Knowledges," Donna Haraway argued that "feminists have to insist on a better account of the world, it is not enough to show radical historical contingency and modes of construction 
for everything." ${ }^{\prime 7}$ In the more recent book Ecological Thinking, Lorraine Code highlighted the ability of her ecological epistemic project to guard "against the subjectivism and/or relativism that have deterred philosophers from granting epistemic significance to place, particularity, imagination, and interpretation." ${ }^{\prime}$

However, it is not always clear how a relativism based on social location is to be avoided, as many critics of feminist work in science are quick to point out. While we feminists attend to the difficult and important task of identifying the multiple influences of "place, particularity, imagination, and interpretation," in science, we need also to be explicit in our explanations of how it is that these influences can at least in principle be identified and their strengths and weaknesses made clear to any knower who cares enough to engage in the question.

I attempted to provide such an explanation in my earliest articulation of the usefulness of Davidson's work to feminists. ${ }^{9}$ There, I argued that an unnecessary level of relativism could be found in some of the early and classic epistemological writings of three influential feminist theorists: Longino, Harding, and Evelyn Fox Keller, and that reworking their arguments in terms of Davidson's model of radical interpretation would avoid the relativist problem..$^{10}$ Beginning with an analysis of Longino's "Can There Be a Feminist Science?" and Science as Social Knowledge, and proceeding to three essays from Keller's collection Secrets of Life, Secrets of Death, I argued that each of these writings employed, unnecessarily, a relativist claim that our theory-choices must be based not just on the empirical evidence, narrowly construed, but must also be relative to a political or cultural "worldview," "explanatory scheme," or "interpretive framework." I showed how this sort of relativism involves the conceptual splitting of the empirical evidence, on the one hand, from the filter of politics or culture, on the other-a split similar to that between "content" and "scheme" critically discussed by Davidson. ${ }^{11}$

I review here the problem of conceptual relativism that I had identified in Harding's articulation of feminist standpoint theory. Harding is appropriately critical of the claim that objective method consists in detecting a one-to-one correspondence between true representations and the world. ${ }^{12}$ She argues that certain aspects of culture, namely the social standpoint of the theorist, filter the correspondence between any one theory and the evidence gathered in support of that theory. Harding makes the Marxist claim that one's social standpoint will "organize and set limits" on one's understanding of the world. ${ }^{13}$ In other words, the choice of which theories of the world we take to be true will be relative, in some way, to our social 
standpoint. In "Rethinking Standpoint Epistemology: What Is 'Strong Objectivity'?" Harding explains her commitment to the general tenets of standpoint theory:

The starting point of standpoint theory—and its claim that is most often misread-is that in societies stratified by race, ethnicity, class, gender, sexuality, or some other such politics shaping the very structure of a society, the activities of those at the top both organize and set limits on what persons who perform such activities can understand about themselves and the world around them. . . . In contrast, the activities of those at the bottom of such social hierarchies can provide starting points for thought-for everyone's research and scholarship_from which humans' relations with each other and the natural world can become visible. This is because the experience and lives of marginalized peoples, as they understand them, provide particularly significant problems to be explained or research agendas. ${ }^{14}$

In Whose Science? Whose Knowledge? Harding responds to worries about conceptual-scheme relativism that might seem to arise from her work, arguing that although every social standpoint filter "organizes and sets limits" on understanding, that is, every filter provides only a partial representation of reality, not all social standpoints generate equally partial representations or beliefs. The social standpoints of women, or feminists with "maximally liberatory social interests," for example, "have generated less partial and distorted beliefs than others." ${ }^{15}$ She explains:

The history of science shows that research directed by maximally liberatory social interests and values tends to be better equipped to identify partial claims and distorting assumptions, even though the credibility of the scientists who do it may not be enhanced during the short run. After all, anti-liberatory interests and values are invested in the natural inferiority of just the groups of humans who, if given real equal access (not just the formally equal access that is liberalism's goal) to public voice, would most strongly contest claims about their purported natural inferiority. Antiliberatory interests and values silence and destroy the most likely sources of evidence against their own claims. That is what makes them rational for elites. ${ }^{16}$

I'm not convinced that her response to relativism works here. Harding rightly criticizes the traditional epistemological view of what she calls "objectivism." The "value-free" approach of objectivism, she argues, results in a "semi-science" that "turns away from the task of critically identifying all those broad, historical social desires, interests, and values that have shaped the agendas, contents, and results of the sciences much as they shape the rest of human affairs." 17 Harding prescribes, instead, "strong objectivity" that extends the idea of scientific research "to include systematic examination of . . powerful background beliefs," thereby "maximizing objectivity." 18 The concern is that strong objectivity is characterized by Harding as 
the critical examination of linguistic or social filters, "the powerful background beliefs" that continually block our knowledge-seeking of the natural realm. Powerful background beliefs operate as filters or conceptual schemes for organizing the data from the natural world. Here a scheme-content relativism begins to reappear in Harding's work. Beliefs that we form about the natural world can never be objectively true or false on her account, only true or false relative to our subjective filters.

Indeed, because Harding acknowledges that all beliefs have a social filter, she disavows the claim that the standpoints of women or feminists will produce objectively true beliefs. ${ }^{19}$ While she purchases some consistency by claiming that all knowledge is somehow distorted by conceptual frameworks, her relativist claim robs her of the foundation she then needs to argue her thesis-namely that the knowledge produced from maximally liberatory social standpoints is less distorted, generally, than that produced from others. On what can this normative comparison be based? For Harding, objective method ("strong objectivity") is simply the least subjective method for judging which conceptual schemes, filters, or interpretive frameworks make for the least opaque filters between us and the world. If this is the case, then, Harding (as well as critics of feminism) is right: We must concede a certain amount of relativism. When feminist scientists and science commentators choose between competing theories, our choice is made on the basis of our feminist political interpretive frameworks, understood not as evidence available for objective adjudication, but as subjective filters that organize the evidence.

\section{A Davidsonian Prescription}

Paralleling the work of many feminist critics of epistemology, Davidson argues against the claim that the objective detection of sensory data, for example, can be used to justify or stand as evidence for beliefs that represent those data. Davidson notes that for the justification process to work, we have to be aware of the detection of sense data, and this awareness is simply another belief. His argument undercuts the naive objectivist attempt to construe awareness of sensory data as an evidential entity that stands independent from our beliefs.

It might seem, however, that in revealing the incoherence of harnessing sensations as independent evidence, Davidson has removed any objective justificatory scheme for our empirical beliefs. This seems to leave us with the relativism encountered by Harding, a relativism that Davidson's model is supposed to avoid. All is not lost, however, as Davidson's model of the 
radical interpreter provides us with a good reason "for supposing most of our beliefs are true that is not a form of evidence." 20

It is important to make clear that the term "most" in the above quotation is not meant as a quantificational claim guaranteeing, for example, that a certain number of our beliefs must be true. Rather, Davidson uses the concept of the radical interpreter to show that the detection of false beliefs requires that we have a background of true beliefs against which the error of the false beliefs can be measured. This latter claim undercuts the global skeptic who wants to make error a general concern, that is, who wants to deny or question the existence or objectivity of norms against which errors can be measured and detected.

Davidson equips the radical interpreter with the abilities of a competent adult speaker of a language. Parachuted into the midst of a foreign land, she has general expectations about how to proceed. She has a sense of basic logical structure, that is, she understands the implications of those elements of a language ("and," "if . . . then," etc.) that give the sentences that contain them their particular logical form. She also has the ability to discern when the speakers of the foreign language are making assertions, that is, expressing, in the form of sentences, beliefs held true (even though, in the beginning, she has no idea what those sentences mean).

Davidson notes that, to make any progress in her new world, the radical interpreter must watch for correlations between types of sounds uttered by the native speakers and the kinds of events in their shared world that caused the utterances. In the beginning this is all she has to go on. She does not have any preconceived notion of the particular semantic role that is played by any particular noises uttered by the native speakers. Rather, at this early stage, the radical interpreter's successful (accurate) identification of the environmental reference that prompted the native speakers' noises is what provides those noises with semantic content in the first place.

The causal triangular relationship between the interpreter, the native speakers' utterances, and the objects and events in their world requires that the interpreter assume the natives are speaking truthfully about their beliefs. Of course, while the adult language user has the ability to recognize when a native speaker is making an assertion, this recognition does not guarantee that the native speaker's assertion is true. But, says Davidson, at the beginning, the radical interpreter must assume that the native speaker's assertions are true. For interpretation to occur she must assume that the same relation between belief and truth holds for those she interprets, as for herself-what Davidson calls "the principle of charity." 
Why is this agreement necessary at the beginning when the interpreter is collecting sentences in the native language and correlating them with the sorts of environmental conditions that prompted the sentences? It is necessary, says Davidson, because to identify her teachers as having any beliefs, she must assume the beliefs they hold are true. Once she has established an empirical base of correlations between their sentences and hers, then she can start to make judgments of inconsistency and falsehood. Before that point, identifying her teachers' beliefs as false would deplete the empirical base from which she needs to begin her interpretative project in the first place. As Jeff Malpas explains, assigning "too much falsity among beliefs undermines the possibility of identifying beliefs at all."21 Identifying falsehoods and misconceptions is "parasitic" on an established coordinate of shared meaning. ${ }^{22}$

It might still be unclear, however, why the existence of a "shared coordinate of meaning" between the native speaker and the radical interpreter guarantees, in Davidson's words, that "it cannot happen that most of our plainest beliefs about what exists in the world are false." ${ }^{23}$ Just because there must be agreement between the radical interpreter and the native speakers' about the truth of basic beliefs does not guarantee that those beliefs are, in fact, true. Davidson responds by examining the concept of truth itself. Where, he asks, do we come up with the concept of objective truth? The answer is in shared language. "Unless a language is shared there is no way to distinguish between using the language correctly and using it incorrectly; only communication with another can supply an objective check." ${ }^{24}$ And communication with another can only start by assuming agreement on what makes utterances true-the principle of charity.

If the principle of charity is a precursor for successful interpretation, this means that truth must be held primitive for words and sentences to be meaningful. This takes us back to the example of the radical interpreter correlating environmental circumstances with basic native utterances. The radical interpreter has no initial preconceptions about how to link a native utterance with specific semantic content. Rather, her attention to the correct (true) reference of the native sentence is what provides her with clues to the meaning of the utterance in the first place. The meaning of an utterance is given by its truth conditions, and not the reverse.

Davidson uses these points about the radical interpreter to support his extensionalist claim that in the simplest cases of beliefs, the events and objects that cause those beliefs (the extension of the beliefs) also determine their contents, or meaning (the intension of the beliefs). ${ }^{25}$ This means that in the simplest cases, there cannot be wholesale slippage between our 
understanding of the meaning of a sentence and our understanding of the conditions that would make that sentence true. Davidson describes this approach to meaning further, in the following passage:

As long as we adhere to the basic intuition that in the simplest cases words and thoughts refer to what causes them, it is clear that it cannot happen that most of our plainest beliefs about what exists in the world are false. The reason is that we do not first form concepts and then discover what they apply to; rather, in the basic cases, the application determines the content of the concept. ${ }^{26}$

Davidson's extensionalist approach to meaning excludes the possibility that the speech of the radical interpreter could be in principle indistinguishable from her teachers and idiosyncratic with respect to meaning. In the case of simple perceptual beliefs, the meaning of her utterances is determined by their being used correctly in the presence of another speaker and the event in the world that caused the utterance. Taking a holistic approach to build from the simpler cases of beliefs to beliefs expressed in more complex value judgments, any idiosyncrasies in the radical interpreter's meaning are in principle available for her correction through a purely extensional examination of how she has applied her referents. Somewhere along the line, any discrepancies can in principle be revealed. There is no subjective "inside" to her beliefs that is relative to her conceptual scheme and inaccessible from the viewpoint of native speakers on the "outside."

Applying Davidson's model of language use to cases like Harding's standpoint theory, we are cautioned against the metaphysical bifurcation of inner, subjective, politically laden filters and external, objective, empirical beliefs. This advice is particularly relevant for addressing the problems that Harding encounters in her arguments about the filtering function of social standpoints. Harding argues that, because interpretive frameworks or cultural worldviews filter any evidence brought forward in support of a scientific theory or hypothesis, we cannot choose between theories or hypotheses simply on the basis of empirical evidence (where empirical evidence is narrowly construed by Harding). On her view, adjudication must ultimately be relative to our political values and worldviews. However, this construal presumes the relativist view that the "empirical evidence" and our feminist "political values" emanate from two metaphysically separate spheres-the first from the objective, external world; the second from the subjective, internal mind (or minds). The "empirical evidence" is construed as providing independent (objective) support for a theory, while political values are viewed as dependent and subjective filters for the evidence.

In response to this claim about the belief-independence of empirical evidence, Davidson reminds us that when we marshal empirical evidence 
in support of a belief or theory, we need first to be aware of the empirical evidence, and that awareness is itself another belief. In the project of marshaling epistemic justification for our individual beliefs, there is no independent, "nonbelief" entity to which we can appeal. The evidence for a belief must itself be a belief. It is also important to see that both our political values and our more straightforwardly empirical commitments are beliefs of this evidential sort. On Davidson's model, even our (feminist) political beliefs must have some weblike relation to empirical evidence, if they are to have any content. And it is this relation that can in principle be shared and evaluated objectively by anyone, regardless of political affiliations and/ or worldviews.

There are a number of ways in which empirically informed feminist political values can interact with and support the more straightforwardly empirical commitments that, together, make up our growing web of beliefs (e.g., our beliefs critical of sexism and oppression in science). Consider, for example, Elizabeth Anderson's discussion of feminist social scientific research on divorce. ${ }^{27}$ Anderson examines feminist political value judgments such as the claim that, women, just like men, cannot be adequately defined by exclusive attention to their relationships to their spouses and children. ${ }^{28}$ Both women and men have needs, desires, and concerns that focus on aspects of their lives other than their families and homes. These sorts of political value judgments have empirical content that can be objectively evaluated, and they are relevant to the question of how to approach the scientific study of divorce. Anderson argues convincingly that the foregrounding of these feminist claims, however controversial to some, can objectively increase the empirical adequacy of research on divorce. ${ }^{29}$ For example, by including this sort of claim, feminist researchers were encouraged to frame questions that allowed for a wider range of responses from the study participants, and hence a more empirically accurate description of the phenomenon. Feminist researchers were able to see what traditional researchers did not, namely that divorce might not always be seen as a negative life event. ${ }^{30}$

This brings us to the second implication of Davidson's model for feminists, namely, his fact-value holism. Recall Longino's acknowledgment that feminists engaged in science studies have to show both "that scientific inquiry is value- or ideology-laden and that it is productive of knowledge." On Davidson's holistic model, these two seemingly contradictory projects are shown to be of a single piece. The empirical beliefs that comprise "scientific knowledge" have no better or worse metaphysical links to the outer, independent objective world than do our beliefs about values, just as our beliefs about values are no more closely related than our more straightforwardly 
empirical beliefs to our inner subjective world. But this is because, on Davidson's view, there is no inner or outer world; there is no metaphysical bifurcation. There is only one world, an objective view of which can be made meaningful only by the language users who are part of it.

Although it is certainly possible that some of the feminist political beliefs and other value judgments that make up our belief webs might be more geographically remote from the simpler perceptual beliefs at the edge of our webs, the holism of Davidson's model indicates that the value judgments are still connected, by some threads, to those simpler beliefs. When we examine meaning on the model of the radical interpreter, we see that changes in those simple beliefs can, and must, in principle, affect our more complex value judgments, even if the effect is only slight. Furthermore, the links to empirical content of any given value judgments are as available to objective adjudication as are our more straightforward descriptive beliefs.

If we take Davidson's meaning holism seriously, then even our more complex political and other value judgments are importantly linked in publicly accessible ways to our more simple perceptual beliefs and, more generally, to our everyday shared experiences about, and in, the world. It is these complicated but, in principle, publicly accessible set of inferential links that give our more complex political beliefs their meaning. By tracing the inferential relationship between our value judgments and our everyday shared experiences, we can begin to adjudicate objectively the truth or falsity of the more complex evaluative judgments. As with even the most basic exchanges, the fact that we can recognize each other as holding these more complex beliefs becomes the route we take for identifying and objectively adjudicating their content. ${ }^{31}$ Such objective adjudication is possible, though, of course, difficult. ${ }^{32}$

The sense of objectivity that Davidson's account reveals in the most general sense, then, is that our beliefs are objectively true or false insofar as their truth-values hold independently of "our will and our attitudes"; their truth-values are "not in general guaranteed by anything in us." 33 Wanting something to be true or false does not make it so. Of course, there are many cases of "self-fulfilling" prophecy as well as placebo effects and other social-psychological phenomena where labeling something or someone can indeed bring about a change in the world, but even these sorts of changes are dependent on the usual physical causal processes. That negative social messages about weight and body image lead some young women to develop eating disorders need not imply that this sort of illness was "willed into being" through some special metaphysical process in the arsenal of 
sexist advertising executives, however much one might begin to suspect just that. ${ }^{34}$

The innocuous notion of independence between our desires and the truth of our beliefs that underlies Davidson's claim that our beliefs can be objectively true or false applies also to the process or method by which we identify true and false beliefs and/or adjudicate between competing beliefs. That is, because the truth-values of beliefs are, in principle, objective, that means that there are features outside of our own wants and desires that we can point to in identifying those truth-values and/or in adjudicating between competing truth claims. We do not have to be neutral toward the truth of any belief in order to hold the belief up to critical scrutiny, that is, in order to give that belief or its opposite a fair hearing. Objective, rational adjudication of beliefs requires not that we be neutral, but that we be tentative and nondogmatic. The very same objective process by which we identified the truth-value of a particular belief can in principle be sensitive to new experiences that require us to change our minds.

Davidson himself does not focus on this methodological aspect of objectivity, perhaps because it tends to be addressed in venues featuring science studies rather than in the terrain of epistemology and philosophy of language. Within science studies, the question usually concerns how best to choose objectively between competing theories, where an objective process of theory-choice usually indicates, at least, a nondogmatic, fallible assessment of the relevant evidence supporting each theory. Applying Davidson's account, the process would involve tracing the public, empirically accessible route by which the content of the beliefs in question was established, and assessing the relevant evidential links between these beliefs and their causes. But again, this adjudication process can in principle be objective, insofar as the truth-values of the competing beliefs at issue are independent of the desires of the holders of the beliefs. This naturalized analysis of the objectivity of theory choice parallels the analysis offered by a number of feminist philosophers of science, such as Alison Wylie's discussion of the "security" of archaeological evidence. ${ }^{35}$

Of course, this Davidsonian-inspired view of beliefs about values as capable of being objectively true or false contrasts with a more popular view of values that focuses on their private or subjective nature-an inner nature that keeps value judgments from being available for objective evaluation. On some interpretations of Hume, for example, it seems that because we cannot find value judgments out in the world, in the way that we can find, say, rocks out in the world, no objective claims can be made about values. However, with Davidson, I don't think that questions of the "location" of 
values (out there, in here) get to the question of the objectivity of values. To put it another way: unless we are operating with some lingering Cartesian dualism, we shouldn't make much metaphysical noise about the difference between beliefs formed "out there" and "in here." It's not that there's no difference between those sorts of beliefs, just not a difference that affects our ability to objectively examine their truth.

Compare the case of making objective claims regarding other sorts of properties, such as weights or colors. There is a fact of the matter about whether something weighs five kilograms rather than ten, or is green rather than red. Insofar as we can make objective judgments about properties such as color or weight, this doesn't commit us to the view that greenness is out there in the world in the same way that rocks are out there in the world.

Note also that just because there is an objective fact about whether these predicates can be applied in any given case does not mean that we would all agree on the application criteria, or that the identification process is going to be straightforward. Compare:

1. Grass is green.

2. A person's sex-chromosomes are causally irrelevant to successful parenting. 3. Individual organisms belong to the same species just in case they can interbreed.

4. Water is the molecule $\mathrm{H}_{2} \mathrm{O}$.

Cases 3 and 4 might stand out as straightforwardly and objectively true descriptive judgments. However, identifying water as the molecule " $\mathrm{H}_{2} \mathrm{O}$ " is controversial. A sample of pure $\mathrm{H}_{2} \mathrm{O}$ does not have the properties many of us would want to associate with water; in large amounts, it is harmful to drink. Indeed the process of identifying macroproperties of the world around us by reference to their molecular properties is still debated within chemistry. Defining species categories is similarly controversial within evolutionary biology, and systematics more generally. In fact, there is probably as much if not more agreement about the application criteria and empirical evidence for the judgments involved in cases 1 and 2 than there is for cases 3 and 4. But, again, even with doubts about application criteria, there is little doubt that there is an objective fact of the matter in each of the above four cases.

So lack of agreement about how to apply a particular predicate is separate from the question of whether that predicate expresses an objective fact of the matter. And just as we would agree that there is a fact of the matter about whether something is green or red, or a member of the same species or not, there is also a fact about whether someone is a good parent and 
whether his or her sex chromosomes figure relevantly in this assignment. We can objectively evaluate whether these predicates are being applied correctly even if the level of agreement about application criteria varies from case to case.

Our judgments of properties such as color are similar to our judgments about properties that express values, for example, judging someone's parenting ability. Indeed, learning the correct application of the color predicate "green" or the value predicate "successful parent" requires the same sort of empirical examination that is required when we identify something as being a certain molecule, or the member of a certain species. There is a difference between each of these concepts and our own particular ability to identify and apply them. We can be right or wrong in our applications-wishing will not make it that something that is green or successful at parenting is instead blue or unsuccessful. There is an objective, though of course contingent, fact of the matter about whether something or someone can be identified as "green," or as a "successful parent," just as there is in the case of defining "species" and "water."

On Davidson's holistic account, to have meaningful beliefs at all, whether they be value judgments or descriptive judgments, is to be practically (e.g., linguistically) enmeshed in a sociophysical relationship with the world around us, including other knowers. The meaning, or cognitive content, of our judgments, both descriptive and evaluative, is produced through a triangulation between ourselves, the fellow creatures with whom we communicate and engage, and the shared bits of the world on which that communication or engagement is focused.

Insofar as value judgments express anything, then-that is, insofar as they are meaningful-they too are beliefs that have been acquired through the usual process of practical engagement with the world through communication with others. Learning to identify someone as a "successful" parent-learning the meaning of this value term-involves learning through experience of the world to successfully classify something as belonging to a particular category, to assign it a property. The same process is used for learning the meaning of the category terms "conducts electricity," "reflects light," and "produces heat." Insofar as values or any other kind of judgments are meaningful, they are beliefs that arise from our experience with the world-that is, they have empirical content, broadly construed.

As Anderson argues, value judgments can be shown to be amenable to reflective deliberation - they do not have to determine, inappropriately, any given interpretation of some other set of judgments. Of course, they might. Anderson argues that "we need to ensure that value judgements do 
not operate to drive inquiry to a predetermined conclusion." ${ }^{36}$ I want to emphasize the holistic point that this same need holds for any judgment. So, while assigning some phenomenon to the category "good" might inappropriately bias our interpretations of any new evidence about that phenomenon, so too might our categorizations of it as "hot" or "reflective." Importantly, in neither case is the categorization or its effect on future interpretations immune from appropriate revision in the light of new experiences. As Anderson herself shows, any judgments can be held dogmatically, though, thankfully, they need not be. Anderson concludes that "from an epistemological point of view, value judgements function like empirical hypotheses." ${ }^{37}$ I go further, making Davidson's holistic point that value judgments, like any other, just are empirical hypotheses, broadly speakinghypotheses that can be subjected to rational processes of adjudication. They would have no meaning otherwise. ${ }^{38}$

\section{Feminist Strategy}

I have argued that there are two important implications of Davidson's work for feminist science studies. The first is the antirelativist point that whatever there is to the meaning of any of our beliefs must in principle be available from the radical interpreter's external, third-person perspective, no matter how different the social locations, worldviews, or standpoints from which the interpreter or interpreted are operating. When feminists acknowledge the importance of social location to scientific inquiry, this acknowledgment does not have to involve an incoherent scheme-content relativism. The second implication of his work is that there is no principled difference in the triangulation process by which we form beliefs concerning basic descriptive features of the world and beliefs concerning evaluative features of the world. Just as with descriptive judgments, feminist and other value judgments get their semantic content from their relationship to the world-a relationship that can, in principle, be objectively adjudicated. In this way, we can show that feminist interpretations of particular scientific studies are better than sexist interpretations-not just better from a feminist standpoint, but objectively so.

One concern that might arise for feminists at this point is that my claims about "objective adjudication" are always modified by the phrase "in principle" - in the practical, political struggles that feminists face, these sorts of idealized Davidsonian arguments might not always be relevant. The possibility of objectively detecting the truth of feminist claims about science, and of persuading the holders of false, sexist beliefs to change their minds, 
however objective a process, is only that-a possibility. There are structural power differences that often materially interfere with the conversations required for this process. Still, I argue that something like this approach, if not sufficient, remains at least a necessary part of the story. ${ }^{39}$

An opposite concern that might arise for feminist strategy is whether my claims about the possibility of the objective detection of true from false beliefs, and the objective truth of beliefs generally, serves to overemphasize the objective at the expense of the recognition of the subjective. Davidson responds to this worry in "Three Varieties of Knowledge":

It may seem that if sharing a general view of the world is a condition of thought, the differences in intellectual and imaginative character among minds and cultures will be lost to sight. If I have given this impression, it is because I have wanted to concentrate on what seems to be primary, and so apt to go unnoticed: the necessary degree of communality essential to understanding another individual, and the extent to which such understanding provides the foundation for the concept of truth and reality upon which all thought depends. ${ }^{40}$

His work is completely compatible, then, with feminist interest in analyzing individual and group differences in the holding of complex beliefs, especially concerning the existence of highly stratified and isolated sets of beliefs arising out of particular social identities (in cultures such as the contemporary United States, beliefs stratified by sex/gender, racial and class divisions). Within science studies, for example, feminists have played an important role in redefining accounts of objectivity that would acknowledge and incorporate the subjective affects of social stratification on scientific theory production and justification.

Another place where feminists sometimes downplay or resist aligning themselves with certain accounts of "truth" concerns our recognition of the power that can be wielded inappropriately by those scientists who, working as part of the larger Western military industrial complex, claim access to objective Truth with a capital "T," that is, "truth" understood as some foundational and metaphysically suspect notion.

For example, in the final two chapters of her more recent book Science and Social Inequality: Feminist and Postcolonial Issues, Harding asks "Are Truth Claims in Science Dysfunctional?" ${ }^{41}$ She begins with the question, "Do we need truth claims?" and continues, "The argument here is that in the case of the sciences, their costs appear to outweigh their benefits. ${ }^{\prime 42}$ On a closer read, the question can be reasonably paraphrased as "Have the truth claims made by various scientists turned out to be as universally and transculturally true as some scientists and folks in the popular science debates believed the claims to be?" The answer to this, as most of us would now respond, 
is "no." This answer, of course, is itself a truth claim-indeed, it is even an objectively true truth claim, if anything is, and it is a truth claim with which Harding would agree.

However, Harding demurs, preferring to split the language of "objectivity" from "truth" here. Once again, though, her main point is that while she is against the notion of (capital " $\mathrm{T}$ ") Truth, she does not embrace epistemological relativism. In other words, she does believe in the coherence of the notions of truth, accuracy, and objectivity applied in more local and metaphysically innocuous terms.

I think that feminist philosophers are right to be suspicious of the usefulness and coherence of metaphysically suspect theories of knowledge, justification, and truth that claim to rise above the empirical and fallible processes and procedures by which all of us come to know our worlds. However, I think that we should not let this suspicion rob of us of the concept of "objective truth" tout court. In the broadly empirical terms described by Davidson, there need be no metaphysical danger in the concept of objective truth. Feminism, by definition, involves "speaking truth to power." We have a number of objective truth claims on our side. When you've got it, use it.

To review, the two concerns about the account of objectivity provided by Davidson that might be of strategic concern to feminists are: first, that the idealized account is impractical and does not go far enough to show how claims to objectivity can aid in the practical, political struggles feminists face; and second, that the account relies too much on claims of objectivity and truth that downplay important subjective and social features of knowledge, with the added worry that claims to certain notions of objective truth can and have been used inappropriately as tools of oppression.

I argue that these two concerns merely reinforce the complex and contingent nature of the problems feminists working in science studies need to address. In some cases, we feminist philosophers should signal the importance of Davidson's work, highlighting the objectivity of belief, including, where relevant, the objectivity of feminist beliefs. In other cases, we should continue our project of illuminating the important, subjective, socially stratified features of belief that remain. However, this illumination itself requires that some baseline notions of objectivity be established, and that the rhetorical ground be cleared of the relativist fodder that often provokes critics of feminism.

Which aspect of the project we emphasize is going to depend on the debate we find ourselves in. The philosophical tools we need to work on these problems need to be specialized for the task at hand, and no one point 
of emphasis is going to cover all situations. I have argued that Davidson's work on radical interpretation, and especially his notion of triangulation, though not initially designed for use in feminist science studies, is, in fact, a particularly useful tool for us. I look forward to seeing more of his work used in these novel contexts. I am confident that he would be pleased.

\section{Notes}

1. The work of Quine, Davidson's mentor, has also proven useful to feminist science studies. See, e.g., Lynn Hankinson Nelson, Who Knows? From Quine to a Feminist Empiricism (Philadelphia: Temple University Press, 1990), and Feminist Interpretations of Quine, ed. Lynn Hankinson Nelson (State College: Pennsylvania State University Press, 2003). The characterization of radical interpretation that follows comes from Sharyn Clough, "Donald Davidson," in The Routledge Encyclopedia of Postmodernism, ed. Charles E. Winquist and Victor Taylor (London: Routledge, 2001), p. 82.

2. Some have argued that empirical studies regarding Chomskyan notions of deep structure show that the brain of the radical interpreter equips her with more tools than Davidson's thought experiment allows. However, it's important to note that Davidson denies only that such neurological infrastructure can provide semantic content. The claim that language acquisition requires syntactical modules in the brain does not conflict with Davidson's claim that only experience and interaction with native speakers can produce meaningful beliefs.

3. See Sharyn Clough, "A Hasty Retreat from Evidence: The Recalcitrance of Relativism in Feminist Epistemology," Hypatia: A Journal of Feminist Philosophy 13: 4 (1998): 88-111; Clough, Beyond Epistemology: A Pragmatist Approach to Feminist Science Studies (Lanham, MD: Rowman \& Littlefield, 2003).

4. See Donald Davidson, "The Objectivity of Values," in his Problems of Rationality (Oxford: Clarendon Press, 2004); Clough, "On the Very Idea of a Feminist Epistemology of Science: Response to Commentators on Beyond Epistemology: A Pragmatist Approach to Feminist Science Studies," Metascience 15 (2006): 27-37; Clough, "Commentary on Elizabeth Anderson's 'Uses of Value Judgments in Science,'” MIT Symposium on Gender, Race, and Philosophy, Jan. 2006 Symposium I (2006), pp. 1-6, <http:// web.mit.edu/sgrp/2006/no1/Clough0106.pdf>; Clough, "Solomon's Empirical/ Non-Empirical Distinction and the Proper Place of Values in Science," Perspectives in Science 16, no. 3 (2008): 265-279; and Clough and Bill Loges, "Racist Value Judgments as Objectively False Beliefs: A Philosophical and Social-Psychological Analysis," Journal of Social Philosophy 39, no. 1 (2008): 77-95.

5. E.g., Hugh Lacey, Is Science Value Free? Values and Scientific Understanding (London: Routledge, 1999); Richmond Campbell, "The Virtues of Feminist Empiricism," Hypatia: A Journal of Feminist Philosophy 9, no. 1 (1994): 90-115; and Elizabeth Anderson, 
"Uses of Value Judgments in Science," Hypatia: A Journal of Feminist Philosophy 19, no. 1 (2004): 1-24.

6. Helen Longino, "Essential Tensions," in Feminist Epistemologies, ed. Linda Alcoff and Elizabeth Potter (New York: Routledge, 1993) p. 345.

7. Donna Haraway, "Situated Knowledges," in her Simians, Cyborgs, and Women: The Reinvention of Nature (New York: Routledge 1991), p. 184.

8. Lorraine Code, Ecological Thinking: The Politics of Epistemic Location (Oxford: Oxford University Press, 2006), p. 6.

9. This next section makes use of arguments from Clough, "A Hasty Retreat" —an essay that Davidson read and about which he offered favorable and positive commentary (personal communication). He proved to be a kind and generous mentor.

10. Longino, "Can There Be a Feminist Science?," Hypatia: A Journal of Feminist Philosophy 2 (1987); Longino, Science as Social Knowledge: Values and Objectivity in Scientific Inquiry (Princeton: Princeton University Press, 1990); Evelyn Fox Keller "Introduction," "Gender and Science: An Update," and "Critical Silences in Scientific Discourse," in her Secrets of Life, Secrets of Death: Essays on Language, Gender, and Science (New York: Routledge, 1992).

11. Davidson, "On the Very Idea of a Conceptual Scheme," in his Inquiries into Truth and Interpretation (Oxford: Clarendon Press, 1984).

12. Sandra Harding, Whose Science? Whose Knowledge? Thinking from Women's Lives (Ithaca: Cornell University Press, 1991); Harding, "Rethinking Standpoint Epistemology: What Is 'Strong Objectivity?'” in Feminist Epistemologies, ed. Linda Alcoff and Elizabeth Potter (New York: Routledge, 1993).

13. Harding, "Rethinking Standpoint Epistemology," p. 54.

14. Ibid.; italics in original.

15. Ibid., pp. 144, 148.

16. Harding, Whose Science? pp. 148-149.

17. Ibid., p. 143.

18. Ibid.

19. Ibid., pp. 185, 149.

20. Davidson, "A Coherence Theory of Truth and Knowledge," in his Subjective, Intersubjective, Objective (Oxford: Clarendon Press, 2001), p.146.

21. Jeffrey Malpas, Donald Davidson and the Mirror of Meaning (Cambridge: Cambridge University Press, 1992), p. 159.

22. I am grateful to Bjørn Ramberg for this interpretive point. 
23. Davidson, "Epistemology Externalized," in Subjective, Intersubjective, Objective, p. 196.

24. Davidson, "Three Varieties of Knowledge," in Subjective, Intersubjective, Objective, p. 157.

25. Davidson, "The Myth of the Subjective," in Subjective, Intersubjective, Objective; "A Coherence Theory of Truth and Knowledge"; "Epistemology Externalized"; and "The Conditions of Thought," in The Mind of Donald Davidson, ed. Johannes Brands and Wolfgang Gombocz (Grazer Philosophische Studien, no. 36; Amsterdam: Editions Rodopi, 1989).

26. Davidson, "Epistemology Externalized," p. 195.

27. Anderson, "Uses of Value Judgments in Science."

28. Of course, to those who hold feminist values, this might sound like a straightforwardly empirical claim. To someone who does not hold feminist values, however, this "straightforward" claim is value-laden through and through (though still, I argue, empirical).

29. Anderson, "Uses of Value Judgments in Science," pp. 12-18.

30. Ibid., p. 13.

31. Portions of this argument about Davidson and the objectivity of value judgments appear in Clough, "On the Very Idea of a Feminist Epistemology," "Commentary on Elizabeth Anderson's 'Uses of Value Judgments in Science,'” "Solomon's Empirical/Nonempirical Distinction and the Proper Place of Values in Science," and Clough and Loges, "Racist Value Judgments as Objectively False Beliefs."

32. See, e.g., Davidson, "The Objectivity of Values."

33. Davidson, "The Problem of Objectivity," in his Problems of Rationality (Oxford: Clarendon Press, 2004), p. 7.

34. My thanks to Paul Griffiths for helping me tease apart the appropriate notions of "independent" at work here.

35. Alison Wylie, "The Constitution of Archaeological Evidence: Gender Politics and Science," in her Thinking from Things: Essays in the Philosophy of Archaeology (Berkeley: University of California Press, 2002). For a recent review of naturalized approaches to objectivity in feminist science studies, see Wylie and Lynn Hankinson Nelson, "Coming to Terms with the Values of Science: Insights from Feminist Science Scholarship," in Value Free Science: Ideal or Illusion?, ed. Harold Kincaid, John Dupré, and Alison Wylie (Oxford: Oxford University Press, 2006).

36. Anderson, "Uses of Value Judgments in Science," p. 11.

37. Ibid. 
38. Sometimes, of course, meaningful empirical claims can also function more like rules or norms, where the assignment of truth-values is beside the point. See, e.g., Michael Hymers's illuminating discussion of Wittgenstein's claim regarding the dual nature of putatively descriptive propositions, like "This is my hand." This proposition can, in some contexts, function as an empirical truth, and sometimes, it can function logically as a rule around which other descriptive claims are organized and evaluated (Michael Hymers, "Putnam and the Difficulty of Renouncing All Theory," International Studies in Philosophy 35, no. 4 [2005]: 55-82). The capacity for a value judgment or a descriptive judgment to be true or false comes with the meaningfulness of the judgment, but the issue of whether truth-values should be assigned in any given case is relative to the context in which the judgment is being used.

39. Portions of this discussion of "feminist strategy" appear in Clough, "Drawing Battle Lines and Choosing Bedfellows: Rorty, Relativism, and Feminist Strategy," in Feminist Interpretations of Richard Rorty, ed. Marianne Janack (University Park: Pennsylvania State University Press, 2010), pp. 155-172.

40. Davidson, "Three Varieties of Knowledge," p. 219.

41. Harding, Science and Social Inequality: Feminist and Postcolonial Issues (Champaign: University of Illinois Press, 2006), reviewed by Clough, "Sandra Harding's Science and Social Inequality," Hypatia: A Journal of Feminist Philosophy 23, no. 2 (2008): 197-202.

42. Harding, Science and Social Inequality, p. 133. 
